\title{
INTENTIONAL NORMATIVISM MEETS NORMATIVE SUPERVENIENCE AND THE BECAUSE CONSTRAINT
}

\author{
Daniel Laurier
}

daniel.laurier@umontreal.ca

\begin{abstract}
I explain and rebut four objections to the claim that attributions of intentional attitudes are normative judgements, all stemming, directly or indirectly, from the widespread assumption that the normative supervene on the non-normative.
\end{abstract}

Keywords

intentional attitudes; normativity; supervenience; essentialism; because constraint

\section{Two Problems for Intentional Normativism}

Most discussions of the thesis that attributions of intentional attitudes are normative judgements take it for granted that it is (at least) sufficient, for a judgement to be normatively contentful (i.e., to involve a normative concept), that it entails (possibly in conjunction with auxiliary premises involving no normative concept) some normatively forceful judgement ${ }^{1}$, where a judgement is said to have normative force when it entails that some agent has some normative status such as being permitted or obliged to do something). To take this for granted is tantamount to endorsing a version of the Is-Ought principle, according to which no non-normatively contentful judgement entails any normatively forceful judgement. But this raises a problem, insofar as this principle seems to conflict with the equally plausible and widely shared intuition that the normative strongly supervenes on (or is determined by) the non-normative, and may thus ultimately prove to be untenable. Given what has just been said, such an outcome would mean that much of the dispute over intentional normativism had been seriously misconceived. Indeed, as Zangwill (2005) and Steglich-Petersen (2008) have recently pointed out, the supervenience of the normative can be seen to raise a difficulty for (at least) certain forms of intentional normativism quite independently of its relation to the Is-Ought principle.

Both Zangwill (2005) and Steglich-Petersen (2008) take intentional normativism as a metaphysical claim concerning the nature, or "essence", of intentional (more

\footnotetext{
${ }^{1}$ A relevant sample would include Kripke (1982), Gibbard (1994), Hattiangadi (2006), Boghossian (2003, 2005), Whiting (2007) and Bykvist and Hattiangadi (2007).
} 
specifically, attitudinal) facts and properties ${ }^{2}$, and accordingly call it "normative essentialism". Strictly speaking, any claim implying that it is part of the essence of any intentional attitude that it be governed by certain normative principles (the nature of which need not concern us here) qualifies as a version of normative essentialism. But it is also widely agreed that normative essentialism is meant to be a conceptual truth, in the sense that it is supposed to flow from the very concepts that we have of the attitudes, that what they are concepts of (i.e., the attitudinal properties) have normative essences. This means that anyone having the capacity to attribute some intentional attitude (i.e., anyone who has mastered some attitudinal concept), must be in a position to know a priori that the property so attributed is subject to certain norms, or in other words, that any attribution of attitude is a normative judgement ${ }^{3}$. Indeed, on this approach, the claim that intentional attitudes have normative essences is taken to rest on the claim that attitudinal concepts are normative. As will become clear below, the direction of explanation is important here: it is not that attitudinal concepts are said to be normative because the corresponding attitudes have somehow been found to have normative essences, but that attitudes are said to have normative essences because the attitudinal concepts are normative in the first place.

The basic idea behind the objection from supervenience can be simply stated thus. It is a conceptual, a priori truth that normative properties supervene on non-normative properties. Thus, if it were a conceptual a priori truth that intentional attitudes are normative properties, it would also be a conceptual a priori truth that intentional attitudes supervene on non-normative properties. But this claim, even if true, is not conceptually true; for it is not conceptually incoherent to suppose (with the "Cartesian" dualists) that intentional attitudes supervene on nothing but themselves, or, as Zangwill (2005: 7) puts it, to imagine that intentional attitudes "lie at the root of all being". Hence, it is not a conceptual truth that intentional attitudes are normative properties. It follows that normative essentialism is either false or no less a posteriori than the claim that water is $\mathrm{H}_{2} \mathrm{O}$. But (or so the argument goes) the claim that normative essentialism is merely $a$

\footnotetext{
${ }^{2}$ They are, of course, not alone in doing this. Wedgwood (2007a, 2007b and 2009) also takes a similar stance.

${ }^{3}$ Neither Zangwill nor Steglich-Petersen makes the distinction between normatively forceful and normatively contentful judgements, but as far as I can see, it is normatively forceful judgements that they have in mind.
} 
posteriori is prima facie quite unappealing, not to mention the fact that it is hard to see on what grounds anyone would want to hold it.

The argument, as stated, seems quite powerful. Moreover, though its primary target is normative essentialism (the idea that intentional attitudes are normative properties), it would seem to carry over to the claim that attitudinal concepts are normative. For how could it be maintained that attributions of attitudes are normative judgements, if it is denied that it is conceptually true that intentional attitudes are normative properties? And even if this were possible, the argument will perhaps not seem less compelling when rephrased so as to make it bear directly on the claim that the attitudinal concepts are normative, along the following lines: it is a conceptual, a priori truth that normative concepts supervene on non-normative concepts, if attitudinal concepts were normative, it would be a conceptual truth that they supervene on nonnormative concepts, but it is not conceptually true that they supervene on non-normative concepts, hence they are not normative ${ }^{4}$.

Thus, the idea that the normative supervenes on the non-normative raises two problems for intentional normativism. The burden of this paper is to find a defensible and plausible way of meeting this double challenge. As it will turn out, the key to the solution is a proper understanding of the relation between the claim that attitudinal properties are normative and the claim that attitudinal concepts are normative. I will first focus on the conflict between the Is-Ought principle and the supervenience of the normative, and come back later to the issues about the a priority of normative supervenience.

\section{The Is-Ought Problem}

As far as I can tell, the only way to show that some not overtly normative concept (such as the concept of belief) nonetheless is normative is by showing it to be suitably related to some normative force conferring concept, i.e., some concept which can be held responsible for the fact that some of the judgements involving it have normative force.

\footnotetext{
${ }^{4}$ Though it is now current practice, thanks to the works of Jaegwon Kim, to think of supervenience as a relation between kinds of properties or states-of-affairs, it may be worth pointing out that it could just as naturally be conceived as a relation between kinds of concepts or judgements (propositions), or indeed, as in Davidson's, as a relation between kinds of predicates or sentences.
} 
This is correct as far as it goes, but leaves it in the dark what is so special about having normative force. What is it that sets normatively forceful judgements apart from all other judgements? Perhaps an answer can be derived from a suitable version of the view that there is an intimate link between (some) first-person normatively forceful judgements and motivation. Indeed, it seems highly plausible that it would be irrational for anyone to (sincerely) make a judgement of the form "I ought to make-it-the-case that P", or of the form "There is some reason for me to make-it-the-case that P", without being, at least to some extent, inclined to make-it-the-case that $\mathrm{P}^{5}$. Related, and often stronger, internalist principles have been defended by a number of eminent philosophers such as Smith (1994), Korsgaard (1996) and Wedgwood (2007a). Needless to say, no such principle has been completely beyond dispute. For my purpose, however, it need not be maintained that any such principle is necessarily and universally true ${ }^{6}$, for what I am after is just some distinctive feature of normatively forceful judgements. Now, it does seem likely that (i) some normative force conferring concepts are such that, in a significant range of cases, first-person normatively forceful judgements involving them satisfy some such internalist principle (let's call them "primary" normative concepts), and that (ii) no non-normatively forceful judgement ever satisfies any such principle. It should be granted that not all normative force conferring concepts can be primary in this sense; i.e., that some normative force conferring concepts are such that no first-person normatively forceful judgement involving them has any special connection with any sort of motivation. For example, it is not even prima facie irrational for one to judge "I am permitted to make-it-the-case that $\mathrm{P}^{\prime \prime}$ without being in the least inclined to make-it-thecase that P. Yet such judgements do count as normatively forceful, since they entail that the agent has some normative status. It may still be the case, however, that all normative force conferring concepts turn out to be internally related to (or somehow explainable in

\footnotetext{
${ }^{5}$ The same would seem to hold for judgements of the form "It is rational for me to make-it-the-case that $\mathrm{P}$ ". If this is correct, then it would be hard to hold that being linked to rational motivation is distinctive of normative concepts without being committed to the concept of rationality itself being normative.

${ }^{6}$ Wedgwood (2007a: 29-31) considers some exceptions to his favoured version of internalism, according to which: necessarily, if one is rational then if one judges "I ought to A", one also intends to A. He observes, for example, that it need not be irrational to judge that one ought to continue breathing for the next five minutes without having the intention to do so. This leads him to suggest that his principle must be understood as being restricted to A-ings of the appropriate kind, where (of course) it is a relatively open question what the appropriate kind is.
} 
terms of) some primary normative concepts (i.e., some normative force conferring concept for which some internalist principle sometimes holds), and this would seem enough to set all normatively forceful judgements apart. I am confident that many people will be prepared to grant that either the concept of (normative) reason or the concept "(ultima facie) ought" may well qualify as primary normative concepts in this sense. In any case, if the foregoing is at all in the right direction, then one distinctive feature of all normatively forceful judgements is that they either directly or indirectly involve primary normative concepts.

The important thing, for our present concerns, is that this distinctive feature doesn't transmit to the corresponding states-of-affairs. Consider the first-person normatively forceful judgement that I ought to make-it-the-case that P. In making such a judgement I am, in effect, judging that I exemplify the property (if any) designated (or determined) by the concept "ought to make-it-the-case that P". It is, however, widely acknowledged that many different concepts may designate one and the same property, and hence, that many different judgements may represent one and the same state-of-affairs. Suppose (i) that it would be irrational for me to judge that I ought to make-it-the-case that $\mathrm{P}$ without being inclined to make-it-the-case that $\mathrm{P}$, (ii) that some other concept $\mathrm{C}$ designates the same property as the concept "ought to make-it-the-case that P" and (iii) that I judge myself to be $\mathrm{C}$. Unless I realize that $\mathrm{C}$ and "ought to make-it-the-case that $\mathrm{P}$ " designate the same property, there is no reason to expect that it would be irrational for me to judge that I am $\mathrm{C}$ without being inclined to make-it-the-case that P. In other words, there is no reason to expect that, if some concept is primary normative, then all co-designating concepts are primary normative as well. But if so, then if any property can be said to be primary normative, it is only in the sense that it is designated by some primary normative concept. In other words, the fact that some concept is primary normative cannot be a reflection of the fact that the property it designates is primary normative (for then all co-designating concepts would have to be primary normative), but on the contrary, the fact that some property is primary normative reflects the fact that it is designated by some primary normative concept ${ }^{7}$.

\footnotetext{
7 This paragraph owes much to Wedgwood's (2007a: 61-65) much more detailed discussion of what is basically the same point.
} 
Suppose it is indeed a distinctive feature of all normatively forceful judgements that they either directly or indirectly involve some primary normative concept. From this, it would of course follow that it is a distinctive feature of the states-of-affairs represented by normatively forceful judgements (assuming there are such states-of-affairs) that they involve some primary normative property (i.e., some property designated by a primary normative concept). But it does not follow that these primary normative properties have any essential, "intrinsic" feature such that no property can have this feature without being designated by some primary normative concept; nor does it follow that there is no such feature: the point is that if there is such a feature, it will not be known a priori, on the sole basis of our possessing some primary normative concepts. All this has interesting implications on how to assess the conflict between the Is-Ought principle and the normative supervenience claim, as I will now explain.

While it has become standard to make a distinction between weak and strong supervenience claims, it must first be registered that weak normative supervenience could not possibly conflict with the Is-Ought principle. On the standard construal of weak supervenience, properties of kind A weakly supervene on properties of kind B if and only if it is necessary that if $x$ has some property $F$ (of kind A) then there is some property $G$ (of kind B) such that $\mathrm{x}$ has $\mathrm{G}$ and for all $\mathrm{y}$, if $\mathrm{y}$ has $\mathrm{G}$ then $\mathrm{y}$ has F. And similarly, concepts of kind A weakly supervene on concepts of kind B if and only if it is necessary that if $\mathrm{x}$ falls under some concept $\mathrm{F}$ (of kind $\mathrm{A}$ ) then there is some concept $\mathrm{G}$ (of kind $\mathrm{B}$ ) such that $\mathrm{x}$ is $\mathrm{G}$ and for all $\mathrm{y}$, if $\mathrm{y}$ is $\mathrm{G}$ then $\mathrm{y}$ is $\mathrm{F}$. It will be convenient to refer to the first relation as one of (weak) "metaphysical" supervenience, and to the second as one of (weak) "conceptual" supervenience. These relations obviously are compatible both with the fact that no property of kind B necessitates any property of kind A and with the fact that no concept of kind B entails any concept of kind $A^{8}$. This is enough to ensure that both the conceptual and the metaphysical versions of the claim that the normative weakly supervene on the non-normative are compatible with the Is-Ought principle, construed either as the conceptual principle that no non-normative judgement entails any normatively forceful judgement, or as the metaphysical principle that no non-normative

\footnotetext{
${ }^{8}$ Here, I am using "necessitate" to refer to metaphysical necessity, and "entail" to refer to conceptual necessity.
} 
state-of-affairs (where a non-normative state-of-affairs is one which is represented by no normatively contentful judgement) necessitates any normative state-of-affairs (where a normative state-of-affairs is one which is represented by some normatively forceful judgement).

Things are quite different when we turn to strong supervenience. For, on the standard construal, properties of kind A strongly supervene on properties of kind B if and only if it is necessary that if $\mathrm{x}$ has some property $\mathrm{F}$ (of kind A) then there is some property $\mathrm{G}$ (of kind B) such that $\mathrm{x}$ has $\mathrm{G}$ and necessarily, for all $\mathrm{y}$, if $\mathrm{y}$ has $\mathrm{G}$ then $\mathrm{y}$ has F. And similarly, concepts of kind A strongly supervene on concepts of kind B if and only if it is necessary that if $\mathrm{x}$ falls under some concept $\mathrm{F}$ (of kind $\mathrm{A}$ ) then there is some concept $\mathrm{G}$ (of kind $\mathrm{B}$ ) such that $\mathrm{x}$ is $\mathrm{G}$ and necessarily, for all $\mathrm{y}$, if $\mathrm{y}$ is $\mathrm{G}$ then $\mathrm{y}$ is $\mathrm{F}$. Accordingly, strong metaphysical supervenience requires that every property of kind A be necessitated by some property of kind B, and strong conceptual supervenience requires that every concept of kind A be entailed by some concept of kind B. Hence, strong metaphysical supervenience of the normative on the non-normative is flatly incompatible with the metaphysical Is-Ought principle, while strong conceptual supervenience of the normative on the non-normative is incompatible with the conceptual Is-Ought principle.

This, in principle, leaves two options to anyone who wishes to preserve both the supervenience and the Is-Ought intuitions: (1) deny strong conceptual supervenience and the metaphysical Is-Ought principle, but embrace strong metaphysical supervenience and the conceptual Is-Ought principle or do the opposite, namely, (2) deny strong metaphysical supervenience and the conceptual Is-Ought principle, but embrace strong conceptual supervenience and the metaphysical Is-Ought principle.

Now, it may seem that option (1) is forced upon us by the fact that, as is generally assumed, conceptual necessity is strictly stronger than metaphysical necessity, or in other words that the judgement (or proposition) that $\mathrm{P}$ is conceptually necessary only if the state-of-affairs represented by this judgement is metaphysically necessary. For, on this assumption, strong conceptual supervenience of the normative would entail strong metaphysical supervenience of the normative, and thus, would be incompatible with both the metaphysical and the conceptual Is-Ought principle. I agree that option (1) is the only 
plausible one available, but this is emphatically not because I hold conceptual necessity to be stronger than metaphysical necessity. For, as will appear below, my answer to Zangwill's and Steglich-Petersen's supervenience objection will commit me to deny this.

In my view, what should lead us to choose option (1) is simply that it is called for by our previous reflections on the distinctive internalist feature of normatively forceful judgements. For what these seem to show is that if there is to be a distinction between normative and non-normative properties/states-of-affairs, it is likely to be a merely "extrinsic" one that derives from a prior distinction between normative and nonnormative concepts/judgements, since it is only at this conceptual level that we were able to find a plausible distinctive feature of normativity (and this feature doesn't carry over to the metaphysical level). Assuming that only normatively forceful judgements have the special connection to rational motivation previously alluded to, it is, indeed, to be expected that no non-normatively contentful judgement entails any normatively forceful one. However, this is perfectly compatible with every state-of-affairs represented by some normatively forceful judgement being necessitated by some state-of-affairs not represented by any normatively contentful judgement. Needless to say, although the conceptual Is-Ought principle is thus compatible with strong metaphysical supervenience of the normative, it certainly doesn't entail it, which suggests that if the normative does indeed strongly metaphysically supervene on the non-normative, it will not be a priori that it does (since for this to be a priori, it would have to rest on some distinctive feature of normative concepts).

On the picture I am sketching, there may or may not be some "intrinsic" distinctive feature of normative properties as such (i.e., one that does not derive from any specific feature of the corresponding normative concepts). I need not take a stand on this issue; though I find it hard to see what kind of feature it might be, given that it would have to be such that necessarily, no property could have it without being designated by some normative concept (i.e., some concept which is "internally" related to some primary normative concept). And it is even harder to see how such a feature could call for a strong supervenience relation, when the distinctive feature of the corresponding concepts pushes in the opposite direction, calling for the denial of just such a relation (at the conceptual level). In any case, if normative properties turn out to have such an intrinsic 
distinctive feature it is most likely to be one that (in Mackie's phrase) will make them "queer" properties, and a substantial argument will then be needed to support any metaphysical supervenience claim. Suppose, on the other hand, that there is no such distinctive feature to be found. There will then be no ontological gap between normative and non-normative properties (i.e., between properties that are designated by some normative concept and properties that are not designated by any normative concept). In this scenario, the claim that the normative metaphysically supervenes on the nonnormative would appear to be more plausible, but at the same time, the need for it would be considerably diminished. For, if there is nothing queer to normative properties as such, why should it be thought that they must strongly (or even weakly) supervene on any other properties? As we will now see, this provides part of the answer to Zangwill's and Steglich-Petersen's supervenience objection.

\section{The Supervenience Objection}

While the problem arising from the Is-Ought principle has to do with strong normative supervenience and is independent of whether the latter is a priori or not, the supervenience objection can work with weak normative supervenience but requires it to be $a$ priori. It is in fact quite easy, given what has been said so far, to answer the objection as originally stated, which was meant as an objection against normative essentialism (i.e., against "metaphysical", as opposed to "conceptual", intentional normativism).

The objection may seem to be that since it is not a priori that intentional properties weakly supervene on non-normative properties, while it is a priori that normative properties weakly supervene on non-normative properties, intentional properties cannot be normative (or more precisely, it cannot be a priori that they are). But, so understood, it is no objection at all. For, assuming it is a priori that normative properties weakly supervene on non-normative properties, it is no less a priori (even trivial) that nonnormative properties weakly supervene on non-normative properties (if only on

themselves). Hence, whether intentional properties are normative or not, (on this assumption) it will in either case be a priori that they weakly supervene on nonnormative properties. 
The real objection actually exploits the fact that if normative properties weakly supervene on non-normative properties, then it follows that they don't supervene merely on themselves, while intentional properties may supervene on non-normative properties merely by supervening on themselves. What it says, in effect, is that it is a priori that normative properties don't weakly supervene merely on themselves, while it is not $a$ priori that intentional properties don't weakly supervene merely on themselves. From this, it does follow that it is not a priori that intentional properties are normative.

Now, my discussion of the relation between the Is-Ought principle and normative supervenience led me to deny that normative concepts strongly supervene on nonnormative concepts, and thus that it is a priori that normative properties strongly supervene on non-normative properties. But I didn't say anything about weak supervenience, except that it was compatible with the Is-Ought principle. At first sight, it may seem that denying strong conceptual supervenience would naturally lead one to question weak conceptual supervenience as well, but it need not do so. Weak conceptual supervenience of the normative rests on the very robust intuition that it would be rationally incoherent to hold that two things which fall under the very same nonnormative concepts nonetheless don't fall under the same normative concepts. It is thus unexceptionable and must be endorsed.

Denying conceptual supervenience requires denying the a priority of metaphysical supervenience (tough not metaphysical supervenience itself). But (or so I submit) one may well embrace conceptual supervenience without being forced to accept metaphysical supervenience: normative concepts may supervene on non-normative concepts without its being a priori that normative properties supervene on non-normative properties. For, as I have remarked above, from the fact that normative concepts have distinctive features that set them apart from other concepts, it does not follow that the properties that they designate are set apart from other properties by anything other than the fact that they are designated by these concepts. It thus remains conceptually possible that normative properties don't weakly supervene on any other properties, even though normative concepts do (weakly) supervene on non-normative concepts.

This is the point at which it becomes apparent that I need to deny that conceptual necessity entails metaphysical necessity. Since such denial is likely to encounter some 
resistance, perhaps I would do well to be more explicit about what I take to be involved in this move. As I will put it, every ("ordinary") concept purports to designate some real, mind-independent property, but not every concept actually succeeds in doing so. Since "purported designation" is an intensional relation, it seems undeniable that a judgement can be conceptually necessary only if the state-of-affairs it purports to designate is "metaphysically" necessary. But since "actual" designation is extensional, there is nothing to prevent a judgement from being conceptually necessary without the state-ofaffairs it "actually" designates being metaphysically necessary ${ }^{9}$. Let me illustrate what I have in mind by way of an example. Consider the concept of a tiger and suppose that it involves that of having stripes, in such a way that it is conceptually necessary that tigers have stripes. Then the concept of tiger purports to designate a property which metaphysically necessitates the property purportedly designated by the concept of having stripes. Yet, for all we know, the property actually designated by the concept of tiger does not metaphysically necessitate the property actually designated by the concept of having stripes. To hold that, on the contrary, there is no metaphysically possible world in which something possesses the property actually designated by the concept of tiger without possessing the property actually designated by the concept of having stripes, is to take it for granted that every metaphysically possible state-of-affairs is also conceptually possible. Now, it may well be defensible to hold that every metaphysically possible state-of-affairs is "in principle" conceivable by someone at some time (i.e., is conceptually possible relative to some system of concepts), but it hardly follows from this that every metaphysically possible state-of-affairs is conceivable by us all the time. If it did, every conceptual change would necessarily be mistaken. Thus, in denying that conceptual necessity entails metaphysical necessity, I am simply denying something that only the most radical global irrealist would want to defend, namely, that every metaphysical possibility is reflected in our current "conceptual scheme".

So, my answer to the original supervenience objection is to deny that it is a priori that normative properties weakly supervene on non-normative properties (not that it is $a$

\footnotetext{
${ }^{9}$ In holding that a concept may "actually" designate something it doesn't purport to designate, I am committed to "actual designation" being, in part, a causal relation. The distinction I have in mind is somewhat analogous to Donnellan's (1966) famous distinction between referential and attributive descriptions.
} 
priori that intentional, attitudinal properties are normative ${ }^{10}$ ). Unfortunately, this cannot be the last word. For, having granted that normative concepts weakly supervene on nonnormative concepts, it may now be contended that intentional concepts don't weakly supervene on any other concepts (if they did, it would of course have to be a priori), from which it would follow that they are not normative (just as it followed from the original argument that it is not a priori that intentional properties are normative). But how are we to assess this contention?

On the face of it, it looks like a flat denial that intentional concepts are normative. Now, each time there is a dispute about whether some concepts do or do not possess some characteristic (i.e., about whether something is or is not a conceptual truth), one side or the other is bound to be conceptually confused or incoherent. Needless to say, the history of philosophy is replete with such conceptual confusions/incoherencies, which only shows that these may be hard to detect. Mutual accusations of conceptual confusions are likely to be sterile, as each side can often enrol a long list of philosophical authorities.

Steglich-Petersen (2008: 274) contends that many philosophers have been committed to Cartesian dualist views requiring that attitudinal properties supervene on nothing but themselves and that it would be incredible that all of them have been conceptually confused. I have already made it clear that, in my view, they need not have been confused about this, even if attitudinal concepts do (weakly) supervene on nonnormative concepts. However, insofar as our current understanding of the distinction between concepts and properties is a fairly recent achievement, I don't find it especially unlikely that these philosophers have indeed been confused about the distinction between conceptual and metaphysical supervenience, or, in general, about modality, intentionality and/or normativity. As far as such historical matters are concerned, then, there is not much to prevent the intentional normativist from digging his/her heels, even if this commits him/her to hold that Cartesian dualists have been conceptually confused. Such a response may well be defensible. But since it allows each party to stick to its guns, it would be somewhat disappointing if nothing more could be said. Fortunately, a better

${ }^{10}$ Though if what I have been saying is correct, from the fact that it is a priori that intentional properties are normative, it doesn't follow that they have normative essences. 
response is available, for it can be argued that Cartesian dualism doesn't actually require that intentional properties supervene on nothing but themselves; and if it doesn't, then its conceptual coherence is no ground for denying that it is conceptually true that intentional properties don't supervene merely on themselves ${ }^{11}$.

As Zangwill (2005: 6) observes, to say that some property has a normative essence is not yet to say that this is the "whole" of its essence, that it has no essential feature besides the one that makes it normative ${ }^{12}$. In other words, that a property counts as normative in virtue of the fact that it has some essential feature doesn't prevent it from having essential features of other kinds as well. Now, suppose that intentional attitudes are just of this sort: their essences have, so to speak, both a normative and a nonnormative part $^{13}$. And suppose further that the normative part is metaphysically necessitated by the non-normative part. In this scenario, intentional properties don't exactly supervene merely on themselves; what they supervene on is something which is part of, but still different from, them. Hence, this is compatible with the claim that intentional properties are normative and strongly supervene on non-normative properties and, a fortiori, with the claim that they are normative and weakly supervene on nonnormative properties. But it is also compatible with the possibility that disembodied minds with various intentional attitudes exist; which, in turn, is not clearly inconsistent with the intuition behind Cartesian dualism. I say "not clearly inconsistent" because perhaps some would want to insist that Cartesian dualism requires not merely that there

\footnotetext{
${ }^{11}$ What follows is my adaptation of a point made by Zangwill (2005: 6-7)

${ }^{12}$ Zangwill puts this in terms of a distinction between a stronger and a weaker form of normative essentialism. In his words (2005: 6), strong normative essentialism is the thesis that "propositional attitudes are normative properties", while weak normative essentialism is the view that "propositional attitudes have essential normative properties" (my emphasis), though these properties do not exhaust their essences. In other words, according to weak normative essentialism, only part of the essence of a propositional (or intentional) attitude is normative; that is to say, on this view, a propositional attitude has both normative and non-normative essential properties (in particular, in Zangwill's view, it is part of its essence that it plays a certain normative role with respect to other attitudes, though it is not to be identified with this role). This seems to be in line with what I say in the text. However, I find Zangwill's way of contrasting "being a normative property" with "having some normative essential property" somewhat unfortunate, since it would seem that "having some essential normative property" is sufficient for being a normative property. As far as I can see, nothing is lost if the contrast is taken to be between "having only normative essential properties" and "having some normative essential property".

${ }^{13}$ If this sounds strange, perhaps it will help to consider the fact that if attitudinal concepts are indeed normative, they can only be what Williams (1985) called "thick" normative concepts, i.e., concepts that have both normative and non-normative aspects/components, by contrast with such "thin" normative concepts as the concepts of obligation or of reason. This lends some plausibility to the claim that the properties that they designate may essentially have both a normative and a non-normative part.
} 
could be disembodied minds with various intentional attitudes, but also that their attitudes could be the only properties that they have; something which would admittedly be incompatible with our scenario. However, this would seem to be a far too specific requirement for something that is supposed to be closer to a "common sense", pretheoretical intuition than to an articulated philosophical thesis. For, it should be clear that "Cartesian" dualism, in this context, doesn't have much to do with any specific historical figure, and is little more than a gesture towards a somewhat ill defined family of views concerning mind and matter. If this is right, then the conceptual coherence of Cartesian dualism is no ground for denying that it is conceptually true that intentional properties don't supervene merely on themselves. Though it requires that disembodied minds could have attitudes without having any properties that are not already part of their having these attitudes, it requires neither that they could have attitudes without having any other properties at all, nor even that they could have attitudes without having any nonnormative properties.

This may be granted to show that its being conceptually true that intentional attitudes are normative and normative properties strongly supervene on non-normative properties doesn't imply that Cartesian dualism is conceptually incoherent. But, it will be asked, what is the use of pointing this out, since I have already denied that it is a conceptual truth that normative properties strongly, or even weakly, supervene on nonnormative properties? What matters here is that it could not be conceptually true that normative properties weakly supervene on non-normative properties unless normative concepts weakly supervened on non-normative concepts. From which it follows that if the claim that it is conceptually true that intentional attitudes are normative and normative properties weakly supervene on non-normative properties is compatible with Cartesian dualism, then so is the claim to which I am actually committed, namely, that attitudinal concepts are normative and normative concepts weakly supervene on nonnormative concepts. In the end, then, my response to the conceptual version of the supervenience objection is to reject the contention that attitudinal concepts don't weakly supervene on any other concepts, and maintain that this is no threat to the conceptual coherence of "Cartesian" dualism. 


\section{The Because Constraint Objections}

The two problems I have identified at the beginning have now been successfully dealt with. But normative supervenience also has something to do with two further objections that have been raised by Steglich-Petersen (2008), and which must now be addressed. Steglich-Petersen appeals to normative supervenience in order to motivate a certain constraint on normative judgements, which then gives rise to two arguments bearing directly on the claim that attributions of attitudes are normative judgements (and thus on the claim that attitudinal concepts are normative), and indirectly on the a priority of normative essentialism. However, since I have already denied that normative essentialism follows from the claim that attributions of attitudes are normative judgements, I will ignore the parts of his two arguments that have to do with normative essentialism. When this is done, the remaining parts can be reconstructed in the following way:

\section{$\underline{\text { Argument A }}$}

(1) It is an a priori requirement on normative judgements that whenever S makes a normative judgement, $\mathrm{S}$ must be prepared to provide a non-normative judgement in support of it.

(2) If attributions of attitudes are normative judgements, then it is an a priori requirement that whenever $\mathrm{S}$ attributes some attitude, $\mathrm{S}$ must be prepared to provide a non-normative judgement in support of it.

(3) It is not an a priori requirement that whenever $\mathrm{S}$ attributes some attitude, $\mathrm{S}$ must be prepared to provide a non-normative judgement in support of it.

Therefore,

(4) Attributions of attitudes are not normative judgements.

\section{Argument B}

(1) It is an a priori requirement on normative judgements that whenever $S$ makes a normative judgement, $\mathrm{S}$ must be prepared to provide a non-normative judgement in support of it.

(5) Judgements of rationality are normative.

(6) It is an a priori requirement that whenever $\mathrm{S}$ makes a judgement of rationality, S must be prepared to provide a non-normative judgement in support of it. 
(7) Attributions of attitudes can act as such support for judgements of rationality.

Therefore,

(4) Attributions of attitudes are not normative judgements.

The premise common to both arguments, premise (1), is the constraint I mentioned above, which Steglich-Petersen (following Zangwill 2006) calls the "Because Constraint". I agree with him that this constraint is at least made plausible by its being $a$ priori that normative concepts weakly supervene on non-normative concepts ${ }^{14}$. To say that normative concepts weakly supervene on non-normative concepts is to say that necessarily, if $x$ falls under some normative concept $F$ then there is some non-normative concept $G$ such that $x$ is $G$ and for all $y$, if $y$ is $G$ then $y$ is $F$. It may thus be granted that if weak normative supervenience is a priori then it is a priori that for any normative judgement there is some non-normative judgement that is (materially) sufficient ground for it and that anyone who has mastered some normative concept can know a priori that this is the case. Nothing strictly follows from this, of course, concerning the kind of grounds on which it would be appropriate (or rational) to make a normative judgement. From the fact that you know a priori that there is some (materially) sufficient nonnormative ground for any true normative judgement that you could make, it doesn't follow that you are never allowed to make a normative judgement unless there is some non-normative judgement that you are prepared to make and that you take as supporting your normative judgement. Yet this constraint does seem plausible, and to the extent that it would not seem plausible at all if normative concepts didn't weakly supervene on nonnormative concepts, it may be said to be supported by weak normative supervenience.

The link between weak normative supervenience and the Because Constraint can perhaps be made more salient in the following way. As has often been pointed out, weak normative supervenience basically is a coherence constraint. It implies that it would be incoherent to judge that $\mathrm{x}$ but not $\mathrm{y}$ falls under some normative concept, and that there is no non-normative difference between $\mathrm{x}$ and $\mathrm{y}$. So, if you have judged that $\mathrm{x}$ falls under some normative concept and that $\mathrm{y}$ doesn't, you are committed to holding that there is some non-normative difference between $\mathrm{x}$ and $\mathrm{y}$. Now, it is plausible that you will not be

${ }^{14}$ Steglich-Petersen doesn't exactly say that normative concepts supervene on non-normative concepts, but he is clearly committed to its being the case, since he explicitly holds that it is a priori that normative properties weakly supervene on non-normative properties. 
justified in holding this unless you are able to mention at least some such non-normative difference (i.e., unless there is some non-normative concept which you hold to apply to $\mathrm{x}$ but not to y). But whenever you apply a normative concept to something, unless you think this concept applies to everything, you may always be challenged to explain why you don't apply this concept to some other thing. Thus, if (it is a priori that) you have to be prepared to meet such challenges, then (it is a priori that) you have to be prepared to mention some relevant non-normative difference.

So I am happy to grant that premise (1) may actually be true. Steglich-Petersen then gives (2008: 274) three arguments to support the crucial premise (3), that it is not an a priori requirement that whenever $\mathrm{S}$ attributes some attitude, $\mathrm{S}$ must be prepared to provide a non-normative judgement in support of it (i.e., that the Because Constraint doesn't apply to attributions of attitudes). All of them fail.

The first is that the Because Constraint doesn't apply to attributions of attitudes because it is not a priori that the latter weakly supervene on non-normative judgements. It thus rests on the supervenience objection that has already been rebutted above. The second argument is that although we often are required to present non-mental, behavioural evidence to support our ascriptions of attitudes, such evidence "could not plausibly be seen as non-normative grounding for normative judgements and the general requirement to present evidence for ones empirical judgements should thus not be confused with the Because Constraint on normative judgements" (2008: 274). It is unclear whether Steglich-Petersen here wants to deny that the requirement to be able to provide non-normative support for one's normative judgements is a requirement to be able to produce non-normative evidence for them. But I see no reason either to deny this or to think one cannot maintain this without confusing the Because Constraint with the requirement to have evidence for one's empirical judgements. As for the contention that the behavioural evidence normally offered as support for our attributions of attitudes "could not plausibly be seen as non-normative grounding for normative judgements", it strikes me as quite unfounded and slightly beside the point, since what matters here is whether it can be seen as non-normative grounding for our attributions of attitudes (not for normative judgements in general). 
Steglich-Petersen's third argument is that "we often take purely mental manifestations such as assertions and first-person ascriptions as entirely sufficient basis for ascribing propositional attitudes, and it is not a conceptual requirement in such cases to hold that anything more is needed to ground the mental ascriptions made" (2008:274). I agree that it is often sufficient, in practice, to offer the judgement, say, that Socrates said that the sky is blue (or that Zeno said that Socrates believes that the sky is blue) in support for the judgement that Socrates believes that the sky is blue, or the judgement that Socrates said that he wanted to wash the dishes in support for the judgement that Socrates wants to wash the dishes. This shows that attributions of intentional attitudes may be appealed to support further attributions of attitudes. But it does nothing to show that the Because Constraint doesn't apply to attributions of attitudes, and it is plainly question-begging to deny that it is a conceptual requirement that these supporting attributions of attitudes themselves be supported by something else. The Because Constraint requires that one always be prepared to give some non-normative judgement as support for one's normative judgements, but it clearly doesn't forbid giving some normative judgement as support for another. And this is fortunate, for it clearly need not be wrong to support the normative judgement, say, that Socrates ought to open the window, by observing that he ought to let some fresh air into the room and he can do it only by opening the window. Moreover, such support may well be sufficient without this implying that the claim that Socrates ought to let in some fresh air need not itself be supported by anything else. Thus the fact that some attributions of attitudes may be supported by further such attributions can have no tendency to show that they are not normative.

I conclude that premise (3) is unwarranted and that argument A clearly fails. And so does argument B (even more so). For, consider premise (7). If it is read as saying that attributions of attitudes can act as non-normative support for judgements of rationality, then the resulting argument is clearly question-begging. But if it is read as saying merely that attributions of attitudes can act as support for judgements of rationality, then the argument is not valid, unless we add the premise that no normative judgement can ever act as support for a normative judgement. But as we have just seen, this extra premise doesn't follow from the Because Constraint, and is in any case quite implausible. 
There is a further point to make in connection with argument B. Though I don't need to deny that judgements of rationality may sometimes be supported by attributions of attitudes, it is worth mentioning that this doesn't seem to be the case of so-called "wide-scope" rationality requirements, such as, e.g., the requirement that one does not combine believing that $\mathrm{P}$, and that $\mathrm{P}$ entails $\mathrm{Q}$ with disbelieving that $\mathrm{Q}$. You don't need to mention any attitude of mine, in order to support the claim that I am subject to such a requirement (which would, indeed, seem to be a priori). Should it turn out that all rationality requirements (or all rationality requirements that are somehow "constitutive" of attitudinal concepts) have wide scope (as Broome has suggested), argument B would then be completely off target.

Steglich-Petersen (2008: 275) actually considers only rationality judgements of the form "It would be rational for S to believe that Q", which it would, of course, be natural to support with such judgements as "S believes that P and that P entails Q". But, natural though it might be, it is in fact anything but clear that such support is (in general) sufficient. What would seem, however, to be sufficient is that it would be rational for S to believe that $\mathrm{P}$ and that $\mathrm{P}$ entails $\mathrm{Q}$. Assuming, with Steglich-Petersen, that judgements of rationality are normative, this is yet another illustration of the fact that a normative judgement may indeed support another (the Because Constraint notwithstanding).

If the foregoing arguments are sound, they show that neither normative supervenience nor the Because Constraint stands in the way of intentional normativism. By the same token, they also suggest that if the latter is to be a priori, it is best understood as a claim about intentional judgements/concepts, and not as a claim about the "essence" of intentional states-of-affairs/properties. For, although normative essentialism does have the resources to answer the supervenience objection as well as the objections from the Because Constraint, it could not be a priori unless it was also a conceptual $a$ priori truth that normative concepts strongly supervene on non-normative concepts, which would conflict with the (conceptual) Is-Ought principle. 


\section{References}

Boghossian, Paul (2003) "The Normativity of Content", Sosa and Villanueva eds. (2003) 3245

Boghossian, Paul A. (2005) "Is Meaning Normative?", Nimtz and Beckermann eds. (2005) 205-218

Broome, John (1999) "Normative Requirements", Dancy ed. (2000) 78-99

Bykvist, Krister and Anandi Hattiangadi (2007) "Does Thought Imply Ought?", Analysis 67, 277-285

Dancy, Jonathan ed. (2000) Normativity, Oxford, Blackwell

Donnellan, Keith S. (1966) "Reference and Definite Descriptions", The Phil. Review 75, 281304

Dreier, James ed. (2006) Contemporary Debates in Moral Theory, Oxford, Blackwell

Gendler, Tamar Szabo and John Hawthorne eds. (2002) Conceivability and Possibility, Oxford, Oxford U. Press

Gibbard, Allan (1994) "Meaning and Normativity", Villanueva ed. (1994) 95-115

Hattiangadi, Anandi (2006) "Is Meaning Normative?", Mind and Language 21, 220-240

Kim, Jaegwon (1993) Supervenience and Mind, Cambridge, Cambridge U. Press

Korsgaard, Christine M. (1996) The Sources of Normativity, Cambridge, Cambridge U. Press

Kripke, Saul (1982) Wittgenstein on Rules and Private Language, Oxford, Blackwell

McLaughlin, Brian P. and Jonathan Cohen eds. (2007) Contemporary Debates in Philosophy of Mind, Oxford, Blackwell

McLaughlin, Brian P., Ansgar Beckermann and Sven Walter eds. (2009) The Oxford Handbook of Philosophy of Mind, Oxford, Oxford U. Press

Millar, Alan (2004) Understanding People: Normativity and Rationalizing Explanation, Oxford, Oxford U. Press

Nimtz, Christian and Ansgar Beckermann eds. (2005) Philosophy-Science-Scientific Philosophy, Paderborn, Mentis

Smith, Michael (1994) The Moral Problem, Oxford, Blackwell

Sosa, Ernest and Enrique Villanueva eds. (2003) Philosophical Issues 13: Philosophy of Mind, Oxford, Blackwell

Steglich-Petersen, Asbjorn (2008) "Against Essential Normativity of the Mental", Phil. Studies 140, 263-283

Villanueva, Enrique ed. (1994) Philosophical Issues 5: Truth and Rationality, Atascadero, Ridgeview

Wedgwood, Ralph (2007a) The Nature of Normativity, Oxford, Oxford U. Press

Wedgwood, Ralph (2007b) "Normativism Defended", McLaughlin and Cohen eds. (2007) 85101

Wedgwood, Ralph (2009) "The Normativity of the Intentional", McLaughlin, Beckermann and Walter eds. (2009) 421-436

Whiting, Daniel (2007) "The Normativity of Meaning Defended", Analysis 67, 133-140

Williams, Bernard (1985) Ethics and the Limits of Philosophy, Cambridge (Mass.), Harvard U. Press

Zangwill, Nick (2005) "The Normativity of the Mental", Philosophical Explorations 8, 1-19

Zangwill, Nick (2006) "Moral Epistemology and the Because Constraint", Dreier ed. (2006) 263-281

Zangwill, Nick (2009) "Normativity and the Metaphysics of Mind", forthcoming in Australasian J. of Phil. 